\title{
Vehicle exhaust exposure in an incident case-control study of adult asthma
}

\author{
L. Modig*, B. Järvholm*, E. Rönnmark ${ }^{\uparrow,+}$, L. Nyström*, B. Lundbäck ${ }^{\uparrow,+}$, \\ C. Andersson ${ }^{\#}$ and B. Forsberg*
}

ABSTRACT: The objective of this case-control study was to evaluate whether traffic-related air pollution exposure at home increases the risk of asthma in adults and to compare two commonly used exposure variables and differences between urban and rural living.

Incident cases of asthma and matched controls of subjects aged 20-60 yrs were recruited in Luleå, Sweden. In total 203 cases and 203 controls were enrolled in the study. Exposure was estimated by traffic flow and measured levels of outdoor nitrogen dioxide $\left(\mathrm{NO}_{2}\right)$ in the surrounding environment of each home, respectively. The relationship between measured levels of $\mathrm{NO}_{2}$ and traffic flow was studied using linear regression.

The results indicated a nonsignificant tendency between living in a home close to a high traffic flow and an increased risk of asthma. The association between asthma and measured $\mathrm{NO}_{2} \mathrm{was}$ weak and not significant, but the skin-prick test result acted as an effect modifier with a borderline significant association among positives. The correlation between traffic flow and outdoor $\mathrm{NO}_{2} \mathrm{Was}$ low.

The results suggest that living close to high traffic flows might increase the asthma incidence in adults, while the tendency for nitrogen dioxide was only seen among atopics. Traffic flow and nitrogen dioxide had a lower than expected correlation.

KEYWORDS: Adults, incident asthma, nitrogen dioxide, traffic flow

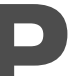

revalence of asthma has increased during the last decades in countries worldwide, including Sweden $[1,2]$. The incidence of asthma has been proven to be highest among children [3,4], but previous studies have also shown relatively high prevalence in adults $[5,6]$. There are several known risk factors for developing asthma, e.g. family history of asthma and allergic sensitisation.

The relationship between outdoor air pollution and airway problems has been investigated in studies with different designs. Several crosssectional studies on children and adolescents have, mainly in children, shown an increased prevalence of wheeze, rhinitis and other respiratory symptoms with increased exposure to vehicle exhausts [7-9]. Few studies have reported air pollution as a cause for asthma. In a 6-yr follow-up study among Japanese children a significant association was found between the annual average concentration of nitrogen dioxide $\left(\mathrm{NO}_{2}\right)$ and the incidence of asthma [10]. A study in the UK showed that children from Birmingham, aged 0-5 yrs, admitted for asthma, were more likely to live in areas with high traffic flows close to their home in comparison with children in a control group [11]. Results from San Diego (USA) showed a weak association in a study among children up to 14-yrs of age [12], while a similar study in London found no associations [13].

Effects on adults have been less frequently investigated. A Japanese study found an increased prevalence of self-reported respiratory symptoms among female adults living close to very busy roads [14]. Corresponding results were also seen for respiratory symptoms among adults in a Swiss study [15]. Among adult nonsmoking males living in California, long-term exposure to ozone increased the risk of developing asthma [16]

Though it is obvious from many previous studies that air pollutants cause adverse effects in the airways, few studies have investigated the relationship between air pollution from traffic and incidence of asthma in adults. The focus in this study is on traffic-related air pollution and the occurrence of asthma among previously nonasthmatic adults, i.e. the incidence of asthma.

\section{Measures of exposure}

Several methods have been applied to measure exposure to traffic pollutants, e.g. participants
AFFILIATIONS

Depts of *Public Health and Clinical

Medicine, and

${ }^{\#}$ Ecology and Environmental

Science, Umeå University, and

'Lung and Allergy Research, National Institute of Environmental Medicine, Karolinska Institutet, Stockholm, and +OLIN Studies, Dept of Medicine Sunderby Central Hospital of Norrbotten, Luleå, Sweden.

CORRESPONDENCE

L. Modig

Dept of Public Health and Clinical Medicine

Umeå University

90187 Umeå

Sweden

Fax: 46907852456

E-mail: lars.modig@envmed.umu.se

Received:

June 172005

Accepted after revision:

February 272006 
own estimation of the flow of traffic around their homes, actual flow of traffic $[8,9]$, or the distance between the home and the nearest big road [17]. $\mathrm{NO}_{2}$ is a commonly used indicator of vehicle exhausts and the connection between $\mathrm{NO}_{2}$ and traffic has previously been demonstrated through correlations with other known traffic-related pollutants [18, 19].

The connection between traffic exposure and respiratory problems has been investigated in a number of studies with both specific pollutant indicators, e.g. $\mathrm{NO}_{2}$, and different measures of traffic density $[8,9,17,20]$. One problem with this variety of exposure indicators is that their associations are not well described. Neither is it known as to what extent they are relevant from a causal perspective. Nowadays $\mathrm{NO}_{2}$ at ambient levels is not judged to be an important pollutant in itself, but rather an indicator of various toxic exhaust components [21].

\section{Aim}

The aim of the present study was to investigate whether trafficrelated air pollution exposure at home, as measured by official information concerning traffic flow and outdoor levels of $\mathrm{NO}_{2}$, increases the risk for developing asthma in adults. Furthermore, the present authors wanted to evaluate the comparability of these two commonly used exposure variables, and finally also study urban versus rural living as a potential determinant for asthma incidence in adults when traffic pollution simultaneously is adjusted for.

\section{METHOD}

\section{Study design and population}

A matched incidence-based case-control study was conducted in Luleå (Sweden), a city with $\sim 71,000$ inhabitants in the northern part of Sweden. The whole municipality covers an area of $\sim 2,100 \mathrm{~km}^{2}$.

The study population consisted of all persons aged 20-60 yrs living in the municipality of Luleå at the time of the study. From September 1995 to December 1999, suspected incident cases of asthma from the primary healthcare, local and county hospitals, private clinics and occupational physicians were reported to the Obstructive Lung Disease In Northern Sweden (OLIN) project. Each case was clinically examined and interviewed before inclusion in the study to verify the onset of asthma within the previous 12 months and bronchial variability. Furthermore, at least four of the following criteria had to be fulfilled to be included as a case in the study: 1) attacks or shortness of breath; 2) wheezing or whistling in the chest; 3) no symptoms between the attacks or periods; 4) at least two provoking factors with the exception of a common cold and physical exertion; and 5) at least two attacks or periods since onset of symptoms.

For each included case a control from Luleå, matched by age and sex, was selected from the Swedish population register. Persons with a diagnosis of asthma, a history of asthma or any previous use of asthma medicines were excluded. Details concerning the study and clinical examination have recently been published [22].

\section{Exposure variables}

\section{Measurement of nitrogen dioxide}

The average levels of outdoor $\mathrm{NO}_{2}$ were measured for a period of 1 week, which was the same for each pair (case and matched control). A Willems badge diffusion sampler was used for the measurements [23]. The sampler was placed $2.5 \mathrm{~m}$ from the ground and $0.5 \mathrm{~m}$ out from the facade on the side of the house least exposed to traffic. The samplers were analysed at Umeå University (Umeå, Sweden) [24]. Due to the lack of capacity, it was not possible to measure $\mathrm{NO}_{2}$ for all pairs. However, there was no geographical or other systematic selection involved in this.

Since ambient $\mathrm{NO}_{2}$ levels in this region, due to emissions and dispersion, vary with temperature, measurements were conducted at different temperatures albeit the same week for pairs, all measured concentrations of $\mathrm{NO}_{2}$ were standardised to correspond with the annual average temperature in the study area. The influence of temperature on the $\mathrm{NO}_{2}$ levels $(\beta)$ was established from a linear regression model, based on $\mathrm{NO}_{2}$ concentrations measured at one urban site between April 1999-March 2000, as a dependent variable and the corresponding weekly temperature averages as independent variables $\left(\beta=-0.63, R^{2}=0.53\right)$. Subsequently every concentration of $\mathrm{NO}_{2}$ measured outdoors over the 1-week period at each home was adjusted to represent an estimated annual average by using the difference between the weekly average and the yearly average temperature together with the regression coefficient.

\section{Traffic flow within different distances from the home}

The participant's residence was located on a map using the official land registry of the area. The road network with the official traffic flow on each road, measured either by the Swedish Road Administration or by the municipal technical office, was added to the map. For each home, a buffer zone with a radius of $200 \mathrm{~m}$ was created. Within each zone, the mean traffic flow (vehicles $24 \mathrm{~h}^{-1}$ period, weekday) for every road crossing the zone was aggregated up to a total flow. Residences where a calculated flow could not be determined, due to lack of traffic counts on the roads within the 200-m radius, were grouped in a low category assuming the flow of 100 vehicles $\cdot 24 \mathrm{~h}^{-1}$.

Usually, several points with traffic counts within $200 \mathrm{~m}$ of the same street are not available. Nevertheless, this was the situation in the most central parts of Luleå with several measurements from the same road in close range due to crossings, while elsewhere this was uncommon. This caused uncertainties in the summarisation of traffic flow and consequently, after checking the registered traffic flows, no participants were given a higher traffic flow than 30,000 vehicles $\cdot$ day $^{-1}$.

A computer software package (ARC VIEW 3.1; Environmental systems research institute, Redlands, CA, USA) was used for the placing of each estate, the creation of radii and the calculation of traffic flow.

\section{Urbanisation}

During the measurement of $\mathrm{NO}_{2}$ the visiting inspector also classified each home in terms of degree of urbanisation into four classes: 1) rural, 2) small house area (residential area), 3) apartment house area, and 4) city centre. In the analyses, cases and controls were categorised as having a rural or urban residence where urban included all classes except rural. 


\section{Statistical methods}

The risks of developing asthma, if exposed to high traffic flow or high $\mathrm{NO}_{2}$ levels at home, respectively, were estimated using odds ratios (OR) calculated in a conditional logistic regression model adjusted for each pair of cases and controls and the variables: family history of asthma, smoking habits, body mass index, rural residence and a positive skin-prick test [25]. Each variable was also tested as an effect modifier in an unmatched logistic regression model adjusted for the above mentioned variables together with age and sex. Of the variables used in the adjustment, some are previously known risk factors for asthma in the studied population and others are more general risk factors [22]. Traffic flow was dichotomously grouped in the analysis of risk estimates, while $\mathrm{NO}_{2}$ was analysed as a continuous variable. The cut-off point for participants living at high traffic flows was chosen as the third quartile $(25 \%$ highest values). The analysis was initially made including all participants and then restricted to those who had lived $>2$ yrs in their home. The analysis of effect modification was done only for the latter subsample. Only the temperature-adjusted $\mathrm{NO}_{2}$ values were included in the models, due to temperature being an important factor for the variation in levels of $\mathrm{NO}_{2}$. Precisions in the point estimates were estimated by calculating $95 \%$ confidence intervals $(\mathrm{CI})$.

A linear regression model was used to study the relation between $\mathrm{NO}_{2}$ and traffic flow. The model included only cases and controls with measured traffic flow within $200 \mathrm{~m}$ and an adjusted $\mathrm{NO}_{2}$ level above the background level $\left(2.5 \mu \mathrm{g} \cdot \mathrm{m}^{-3}\right)$.

\section{RESULTS}

In total 203 cases and controls, respectively, were included in the study. The mean age was 36 yrs. Among the cases and controls 123 were females and 80 males. At the time of the study 125 cases $(\sim 60 \%)$ and 139 controls $(\sim 70 \%)$ had lived $>2$ yrs in their present home. The prevalence of current smoking was $25 \%$ among the cases and $23 \%$ among the controls.

\section{Exposure variables}

$\mathrm{NO}_{2}$ levels outdoors at home were obtained for 138 cases and 136 controls. The median levels of $\mathrm{NO}_{2}$ outdoors are presented for cases and controls in table 1. The measured levels of $\mathrm{NO}_{2}$ were considered low in a European perspective. Estimated annual mean values, adjusted for temperature, were in the range of $2.5-30 \mu \mathrm{g} \cdot \mathrm{m}^{-3}$.

Of the study population $\sim 95 \%$ had geographically coded addresses, which was a requirement for summarising traffic flow around the home. However, $47 \%$ of the controls and $51 \%$ of the cases lived in areas with roads for which there were no available traffic counts, and thus received the traffic flow 100 vehicle $\cdot 24 \mathrm{~h}^{-1}$.

A classification of degree of urbanisation was possible for 197 cases and 193 controls. All but 11 cases and 15 controls had a home address that was possible to retrospectively code geographically but among these urbanisations, classifications were missing for five cases and nine controls. For the 12 participants with homes classified by degree of urbanisation but without geographical codes, the classification was used to estimate their traffic flow around their home. Since none of the 12 participants' homes were classified as city centre, all were given an estimated traffic flow of 100 vehicle $\cdot$ day $^{-1}$. In addition, a sensitivity analysis showed that removing cases and controls without geographically coded home addresses from the analysis did not change the risk estimates.

Among cases and controls classified as having rural homes $\sim 90 \%$ received the flow 100 vehicles $\cdot$ day $^{-1}$, while the corresponding proportion in those classified as having a home in the city centre was only $5 \%$.

Altogether, 15 cases and 17 controls had their summarised flow reduced to the maximum traffic flow of 30,000 vehicles $\cdot 24 \mathrm{~h}^{-1}$.

The distribution (\%) of cases and controls within the categorical variables used in the analysis is shown in table 2. The distributions are given separately for the whole material and for those who have lived $>2$ yrs in there present home.

\section{Relation between nitrogen dioxide and traffic flow}

$\mathrm{NO}_{2}$ was expected to increase with an increased flow of traffic. The relation between outdoor $\mathrm{NO}_{2}$ and traffic flow is shown in figure 1 . The correlation between traffic flow surrounding the home and measured levels of $\mathrm{NO}_{2}$ was quite low $(\mathrm{r}=0.38)$.

\section{Vehicle-exhaust exposure and asthma}

Traffic flow increased the risk of developing asthma, however, not significantly. This was seen both when including all participants and when the analysis was restricted to those who had lived $>2$ yrs in their present home (table 2).

The analysis of asthma in relation to measured levels of $\mathrm{NO}_{2}$ showed no association to suggest that high $\mathrm{NO}_{2}$ levels to be a risk for developing asthma $\left(\mathrm{OR}=1.0\left(\mu \mathrm{g} \cdot \mathrm{m}^{-3}\right)^{-1}, 95 \% \mathrm{CI} 0.9-1.1\right)$. A similar result was found also when restricting the analysis to those who had lived for $>2$ yrs in their present home $\left(\mathrm{OR}=1.1\left(\mu \mathrm{g} \cdot \mathrm{m}^{-3}\right)^{-1}, 95 \% \mathrm{CI} 0.9-1.2\right)$. In the logistic regression analysis of potential effect modification, skin-prick test was a significant effect modifier in the analysis with $\mathrm{NO}_{2}$, which is the reason that the analysis was made separately for those with and without a positive skin-prick test. A borderline significant effect of $\mathrm{NO}_{2}$ on the risk of developing asthma was seen among participants with a positive skin-prick test $\left(\mathrm{OR}=1.2\left(\mu \mathrm{g} \cdot \mathrm{m}^{-3}\right)^{-1}\right.$, 95\% CI 1.0-1.3).

The current results also indicate an increased risk of developing asthma in rural areas, though not significant (table 3).

\section{DISCUSSION}

The results from this study showed that vehicle exhausts indicated by traffic flow surrounding the home had a nonsignificant tendency to increase the risk of developing asthma. For $\mathrm{NO}_{2}$ there was no indication of a relationship when the entire data set was used as a whole. However, onethird had lived $<2$ yrs at the studied address. Among participants who had lived $>2$ yrs in their home and had positive skin-prick tests, elevated levels of $\mathrm{NO}_{2}$ outside the home were significantly associated with incident asthma.

\section{Associations with asthma}

Studies of environmental risk factors for asthma incident among adults are rare and only a few studies have considered air pollutants. MCDONNELL et al. [16] found long-term exposure 
TABLE 1 Traffic flow (vehicles·day $\left.{ }^{-1}\right)$ and outdoor nitrogen dioxide $\left(\mathrm{NO}_{2}\right)$ levels in cases and controls

\begin{tabular}{|c|c|c|c|c|c|c|}
\hline \multirow[t]{2}{*}{ Traffic indicator } & \multicolumn{2}{|c|}{ Entire study population } & \multicolumn{2}{|c|}{ Lived $>2$ yrs in present home } & \multicolumn{2}{|c|}{ Nonrural population } \\
\hline & Cases & Controls & Cases & Controls & Cases & Controls \\
\hline \multicolumn{7}{|c|}{ Traffic flow vehicles day ${ }^{-1}$} \\
\hline Subjects $n$ & 199 & 196 & 124 & 135 & 160 & 168 \\
\hline Median & 100 & 350 & 100 & 100 & 3000 & 1950 \\
\hline \multicolumn{7}{|c|}{ Outdoor ${ }^{\#} \mathrm{NO}_{2} \mu \mathrm{g} \cdot \mathrm{m}^{-3}$} \\
\hline Subjects $n$ & 138 & 136 & 92 & 97 & 108 & 116 \\
\hline Median & 6.5 & 6.0 & 6.0 & 6.0 & 8.0 & 7.0 \\
\hline Range & $0-27$ & $1-23$ & $0-21.2$ & $1-23$ & $1-27$ & $1-23$ \\
\hline Third quartile & 11.0 & 11.0 & 10.8 & 10.5 & 11.8 & 12.0 \\
\hline \multicolumn{7}{|c|}{ Outdoor $\mathrm{NO}_{2} \mu \mathrm{g} \cdot \mathrm{m}^{-3}$} \\
\hline
\end{tabular}

to ozone to be a risk factor for asthma among males aged 27-87 yrs, but not for females. A newly published study from the USA showed significant associations between doctors diagnosing asthma among children and the traffic volume within $150 \mathrm{~m}$ surrounding their home [26]. The current study gives some support for an effect of traffic pollutants by suggesting a nonsignificant increased risk for incident asthma with exposure to high traffic flow surrounding the home.

The geographical information used for the exposure assessment was the home address when entering the study. Consequently, there is likely to be exposure misclassification for participants that recently moved to their present home if the relevant exposure window is several years. The current authors, therefore, focused on those who had lived $>2$ yrs at their present home. This eliminated $36 \%$ of the cases and $30 \%$ of the controls, but increased the risk estimate for high traffic flow to an OR of 2.4, still nonsignificant. Of the participants $\sim 50 \%$ received the traffic flow of 100 vehicles $\cdot$ day $^{-1}$ due to missing traffic counts, which contributed to the uncertainties in the effect estimates.

The effect estimate calculated for $\mathrm{NO}_{2}$ was low when restricting the analysis to those who had lived for $>2$ yrs in

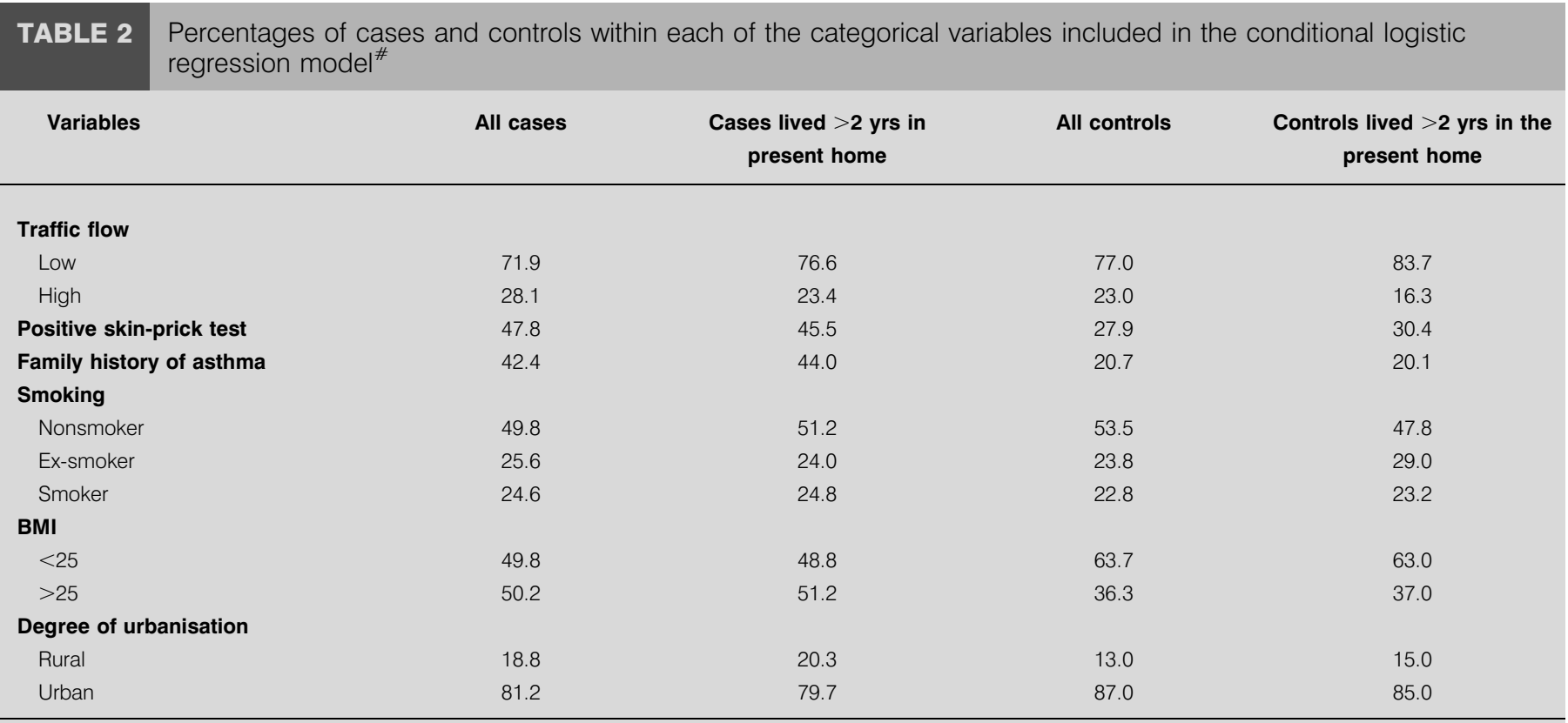

Data are presented as per cent. BMI: body mass index. ${ }^{*}$ : the distributions are given for all participants and those who have lived $>2$ yrs in their home, separately. 


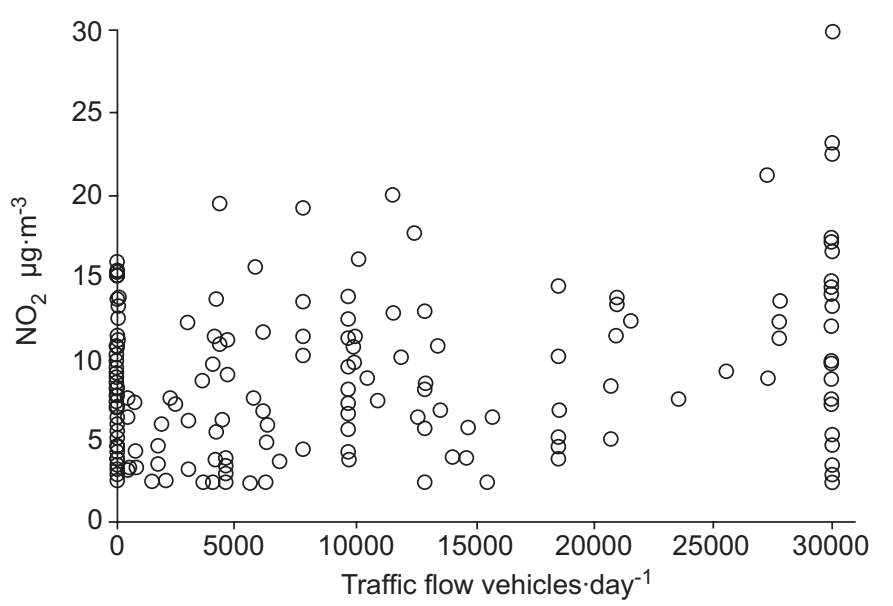

FIGURE 1. Scatter plot of nitrogen dioxide $\left(\mathrm{NO}_{2}\right)$ levels outside by traffic flow within $200 \mathrm{~m}$ of each case's and control's home. Cases and controls without a calculated traffic flow received the flow 100 vehicle.day $^{-1}$ and no participants received a flow $>30,000$ vehicles $\cdot$ day $^{-1}$.

their present home. When the current authors studied those who had lived $>2$ yrs in their present home and had a positive skin-prick test, levels of $\mathrm{NO}_{2}$ outside of the home were associated with an increased risk $(\mathrm{p}=0.04)$ of developing asthma. Living close to highly trafficked roads [27] and $\mathrm{NO}_{2}$ outside the home [28] has, in some studies, proven to increase the risk for a positive skin-prick tests, which is a well known risk factor for developing asthma. Adjusting for a positive skinprick test in stable residents may partly hide an association between asthma risk and previous exposure to traffic pollutants. The findings on traffic pollution and atopy, as well as asthma, are not consistent and therefore further incidencebased studies are needed to confirm the strong effect seen in this small study.

Rural living showed a tendency to increase the risk of developing asthma when traffic pollution is adjusted for. Rural living could be seen as an indicator of a certain lifestyle and different exposure patterns. Previously published studies have shown rural living to be protective against several different respiratory symptoms, especially when rural includes living on or close to a farm $[29,30]$. However, there are other studies in line with the current findings showing higher prevalence of asthma among adults living in rural areas in comparison with urban areas [31].

\section{Calculation of traffic flow}

A geographical information system has been used to describe exposure in several different types of epidemiological studies $[12,32]$. A problem with the geographical location of residences in the current study is that this was based on official information that linked addresses to the centre point of the estate and not the actual building. There is consequently a risk that the zones have not been correctly created around the residences, but around another point within the estate, which could result in an over or underestimation of the traffic flow. The problem is smaller in cities than in rural areas, owing to the fact that estates are normally quite small in densely populated areas. In practice for this study the mentioned risk for under or overestimation is of less importance due to the low traffic flows in the rural areas.

TABLE 3 Associations from a conditional logistic regression analysis of the impact of traffic flow, outdoor nitrogen dioxide ( $\mathrm{NO}_{2}$ ) and urban versus rural living on the risk for developing asthma

\begin{tabular}{|c|c|c|c|c|c|c|}
\hline & \multicolumn{3}{|c|}{ All participants } & \multicolumn{3}{|c|}{ Lived $>2$ yrs in present home } \\
\hline & Subjects $n$ & OR & $95 \% \mathrm{Cl}$ & Subjects $n$ & OR & $95 \% \mathrm{Cl}$ \\
\hline \multicolumn{7}{|c|}{ Conditional logistic regression } \\
\hline \multicolumn{7}{|l|}{ Traffic flow } \\
\hline Low & 379 & $1^{\#}$ & & 208 & $1^{\#}$ & \\
\hline High & & $1.5^{\#}$ & $0.9-2.5$ & & $2.4^{\#}$ & $0.9-6.2$ \\
\hline \multicolumn{7}{|l|}{ Degree of urbanisation } \\
\hline Urban & 379 & $1^{\bullet}$ & & 208 & $1^{\bullet}$ & \\
\hline Rural & & $1.6^{\bullet}$ & $0.9-3.1$ & & $2.1^{\circ}$ & $0.8-5.6$ \\
\hline Urban & 261 & $1^{+}$ & & 156 & $1^{+}$ & \\
\hline Rural & & $1.5^{+}$ & $0.7-3.3$ & & $2.0^{+}$ & $0.6-6.3$ \\
\hline
\end{tabular}

The table shows results for an unconditional analysis of $\mathrm{NO}_{2}$ made among those with positive and negative skin-prick tests (SPT), separately. Results are shown for analyses including all participants and those restricted to persons who lived $>2$ yrs in their present home separately. OR: odds ratio; $95 \%$ Cl: $95 \%$ confidence intervals. ${ }^{\#}$ : adjusted for rural residence, SPT, family history of asthma, body mass index (BMI) and smoking; ${ }^{\bullet}$ : adjusted for traffic flow, SPT, family history of asthma, BMI and smoking; ${ }^{+}$: adjusted for $\mathrm{NO}_{2}$, SPT, family history of asthma, BMI and smoking; ${ }^{\S}$ : adjusted for age, sex, rural residence, family history of asthma, BMI and smoking. 
Residences for which traffic flow could not be calculated were placed in the lower exposure category in the analyses. For the majority of these residences $(93 \%)$ the absence of traffic flow information was due to the lack of traffic counts for the roads within a $200-\mathrm{m}$ radius surrounding the home, while only $7 \%$ were missing in the official land registry and not possible to code geographically.

Of those residences where actual flows could not be determined, $76 \%$ were classified as situated in rural or small house areas by the visiting environmental health officer and of those given the maximum traffic flow $\left(30,000\right.$ vehicles $\cdot$ day $\left.^{-1}\right)$, $94 \%$ were classified as found in a city centre or apartment areas. This indicates that the largest number of participants where traffic flow could not be determined lived outside the city centre, while those exposed to the highest flow lived in the most central areas of the city. The main traffic in this area is focused to the city and a few large roads, while rural and small house areas are generally spared from high traffic flow. The current authors' judgements are that the risk of misclassification by assigning these participants the traffic flow 100 vehicle $\cdot$ day $^{-1}$ is very small and a better option than excluding them from the analysis. An analysis made including only participants with available traffic counts would not only dramatically reduce the number of cases and controls, but the regrouping into new quartiles would also reduce the differences in traffic flow (exposure) between the exposed and unexposed group.

The summarisation of traffic flow was made unweighted, which means that flows were added up independently of where or how much of the roads that crossed through the 200$\mathrm{m}$ radius. The distance to the included roads was not calculated since the current focus was on the flow within the radius, but also because the coordinates for the centre point of the radius showed the centre of the estate and not the participant's home, which could be a problem especially in the more central parts of the city with many roads relatively close to the buildings.

\section{Measurements and adjustment of nitrogen dioxide}

The $\mathrm{NO}_{2}$ samplers were placed on the least trafficked side of the house, since most Swedish block houses in cities have their air intake on this side of the house or on the roof. Swedes also tend to avoid traffic noise, so aired bedrooms are often situated on the quieter side of the house. For the comparison with summarised levels of traffic flow this placement of samplers could be questionable, but the fact that traffic flow was summarised unweighted for distance to road makes the two measures more comparable.

As a sensitivity analysis of the adjustment of measured $\mathrm{NO}_{2}$ values based on temperature, a second type of standardisation was carried out based on 29 weekly measured averages of $\mathrm{NO}_{2}$ from one site in the centre of Luleå. The ratio between weekly concentrations and the annual average at this measurement site was calculated and used to adjust the measured values at each participant's home during the same week. The results from the two methods were highly correlated $(r=0.91)$. The adjustment based on continuous measurements from a central measuring station could seem more appropriate, but lack of weekly measurements throughout the study period made this impossible.

\section{Nitrogen dioxide indicated by traffic flow}

Incomplete traffic counts on minor roads and fewer larger roads resulting in $\mathrm{NO}_{2}$ levels close to background levels is most likely to be the explanation for the low correlation between the estimated yearly outdoor $\mathrm{NO}_{2}$ concentration and traffic flow within a 200-m radius. Surrounding buildings and topography are also important factors in the more trafficked areas.

The majority of traffic-related $\mathrm{NO}_{2}$ is secondarily formed by the oxidation of $\mathrm{NO}$, which suggests that $\mathrm{NO}_{\mathrm{x}}\left(\mathrm{NO}+\mathrm{NO}_{2}\right)$ would have been a better indicator of exhaust fumes. However, at the time of these measurements $\mathrm{NO}_{2}$ was and still is the primary indicator for vehicle exhausts.

The explained variation between traffic flow and nitrogen dioxide together with the results from the analysis shows that classification of traffic pollution on the basis of one method does not guarantee the same results as data collected with another method. Probably the difference between the exposure variables would decrease if the same comparison was made in a larger city. In the area currently studied, traffic is the major source of nitrogen dioxide and several different studies confirm rising outdoor levels of nitrogen dioxide with increased density of traffic and decreased distance from high traffic flow $[33,34]$. However, the use of geographical exposure indicators (e.g. the location of the residences in relation to the source) has been discussed in previous papers and the need for complementary measurements to follow-up and confirm exposure estimates has been stressed [35]. These results further substantiate this discussion and highlight the difficulties of using exposure indicators.

\section{REFERENCES}

1 Woolcock AJ, Peat JK. Evidence for the increase in asthma worldwide. Ciba Found Symp 1997; 206: 122-134.

2 Lundbäck B. Epidemiology of rhinitis and asthma. Clin Exp Allergy 1998; 28: 3-10.

3 Strachan DP, Butland BK, Anderson HR. Incidence and prognosis of asthma and wheezing illness from early childhood to age 33 in a national British cohort. BMJ 1996; 312: 1195-1199.

4 Rönmark E, Perzanowski MS, Platts-Mills T, Lundbäck B. Incidence rates and risk factors for asthma among school children: a 2-year follow-up report from the Obstructive Lung Disease in Northern Sweden (OLIN) studies. Respir Med 2002; 96: 1006-1013.

5 Rönmark E, Lundbäck B, Jönsson E, Jonsson A-C, Lindström M, Sandström T. Incidence of asthma in adults - report from the Obstructive Lung Disease in Northern Sweden study. Allergy 1997; 52: 1071-1078.

6 Lundbäck B, Rönmark E, Jönsson E, Larsson K, Sandström T. Incidence of physician-diagnosed asthma in adults - a real incidence or a result of increased awareness? Report from the Obstructive Lung Disease in Northern Sweden Studies. Respir Med 2001; 95: 685-692.

7 Montnémery $\mathrm{P}$, Popovic M, Andersson M, et al. Influence of heavy traffic, city dwelling and socio-economic status on 
nasal symptoms assessed in a postal population survey. Respir Med 2003; 97: 970-977.

8 Duhme H, Weiland S, Keil U, et al. The association between self-reported symptoms of asthma and allergic rhinitis and self-reported traffic density on street of residence in adolescents. Epidemiology 1996; 7: 578-582.

9 Ciccone G, Forastiere F, Agabiti N, et al. Road traffic and adverse respiratory effects in children. Occup Environ Med 1998; 55: 771-778.

10 Shima M, Nitta Y, Ando M, Adachi M. Effects of air pollution on the prevalence and incidence of asthma in children. Arch Environ Health 2002; 57: 529-535.

11 Edwards J, Walters S, Griffiths RK. Hospital admissions for asthma in preschool children: relationship to major roads in Birmingham, United Kingdom. Arch Environ Health 1994; 49: 223-227.

12 English P, Neutra R, Scalf R, Sullivan M, Waller L, Zhu L. Examining associations between childhood asthma and traffic flow using a geographic information system. Environ Health Perspect 1999; 107: 761-767.

13 Wilkinsson P, Elliott P, Grundy C, et al. Case-control study of hospital admission with asthma in children aged 5-14 years: relation with road traffic in north west London. Thorax 1999; 54: 1070-1074.

14 Nitta H, Sato T, Nakai S, Maeda K, Aoki S, Ono M. Respiratory health associated with exposure to automobile exhaust. I. Results of cross-sectional studies in 1979, 1982 and 1983. Arch Environ Health 1993; 48: 53-58.

15 Zemp E, Elsasser S, Schindler C, et al. Long-term ambient air pollution and respiratory symptoms in adults. Am J Respir Crit Care Med 1999; 159: 1257-1266.

16 McDonnell WF, Abbey DE, Nishino N, Lebowitz MD. Long term ambient ozone concentration and the incidence of asthma in non-smoking adults: the AHSMOG Study. Environ Res 1999; 80: 110-121.

17 Vliet $\mathrm{P}$, Knape M, Hartog J, Janssen N, Harssema H, Brunekreef B. Motor vehicle exhaust and chronic respiratory symptoms in children living near freeways. Environ Res 1997; 74: 122-132.

18 Pekkanen J, Timonen KL, Ruuskanen J, Reponen A, Mirme A. Effects of ultrafine and fine particles in urban air on peak expiratory flow among children with asthmatic symptoms. Environ Res 1997; 74: 24-33.

19 Modig L, Sunesson A-L, Levin J, Sundgren M, HagenbjörkGusafsson A, Forsberg B. Can $\mathrm{NO}_{2}$ be used to indicate ambient and personal levels of benzene and 1, 3-butadiene in air? J Environ Monit 2004; 6: 957-962.

20 Forsberg B, Stjernberg N, Wall S. Prevalence of respiratory and hyperreactivity symptoms in relation to levels of criteria air pollutants in Sweden. Eur J Public Health 1997; 7: 291-296.

21 World Health Organization (WHO). Health aspects of air pollution with particulate matter, ozone and nitrogen dioxide. Report on a WHO working group. Bonn, WHO, 2003.
22 Rönnmark E, Andersson C, Nyström L, Forsberg B, Järvholm B, Lundbäck B. Obesity increases the risk for incident asthma among adults. Eur Respir J 2005; 25: 282-288.

23 Willems JJH, Hofscreuder P, eds. Field Intercomparison Exercise On Ammonia And Ammonium Measurement. Air Pollution Research Report 37. Brussels, Commission of the European Communities, 1991.

24 Hagenbjörk-Gustafsson A, Forsberg B, Hestvik G, Karlsson D, Wahlberg S, Sandström T. Measurements of indoor and outdoor nitrogen dioxide concentrations using a diffusive Sampler. Analyst 1996; 121: 1261-1264.

25 Kleinbaum DG, Klein M. Logistic Regression, A Self Learning Text, 2nd Edn. New York, Springer Verlag, 1994.

26 Gauderman JW, Avol E, Lurmann F, et al. Childhood asthma and exposure to traffic and nitrogen dioxide. Epidemiology 2005; 16: 737-743.

27 Janssen N, Brunekreef B, Vliet $\mathrm{P}$, et al. The relationship between air pollution from heavy traffic and allergic sensitization, bronchial hyperresponsiveness, and respiratory symptoms in Dutch schoolchildren. Environ Health Perspect 2003; 111: 1512-1518.

28 Krämer U, Koch T, Ranft U, Ring J, Behrendt H. Trafficrelated air pollution is associated with atopy in children living in urban areas. Epidemiology 2000; 11: 64-70.

29 Filipiak B, Heinrich J, Schäfer T, Ring J, Wichmann HE. Farming, rural lifestyle and atopy in adults from southern Germany - results from the MONICA/KORA study Augsburg. Clin Exp Allergy 2001; 31: 1829-1838.

30 Leynaert B, Neukirch C, Jarvis D, Chinn S, Burney P, Neukirch F. Does living on a farm during childhood protect against asthma, allergic rhinitis, and atopy in adulthood? Am J Respir Crit Care Med 2001; 164: 1829-1834.

31 Turkeltaub PC, Gergen PJ. Prevalence of upper and lower respiratory conditions in the US population by social and environmental factors: data from the second National Health and Nutrition Examination Survey, 1976 to 1980 (NHANES II). Ann Allergy 1991; 67: 147-154.

32 Bellander T, Berglind N, Gustavsson P, et al. Using geographic information systems to asses individual historical exposure to air pollution from traffic and house heating in Stockholm. Environ Health Perspect 2001; 109: 633-639.

33 Raaschou-Nielsen O, Olsen JO, Hertel O, et al. Exposure of Danish children to traffic exhaust fumes. Sci Total Environ 1996; 189-190: 51-55.

34 Nakai S, Nitta H, Maeda K. Respiratory health associated with exposure to automobile exhaust II. Personal $\mathrm{NO}_{2}$ exposure levels according to distance from the roadside. $J$ Expo Anal Environ Epidemiol 1995; 5: 125-136.

35 Huang YL, Batterman S. Residence location as a measure of environmental exposure: a review of air pollution epidemiology studies. J Expo Anal Environ Epidemiol 2000; 10: $66-85$. 